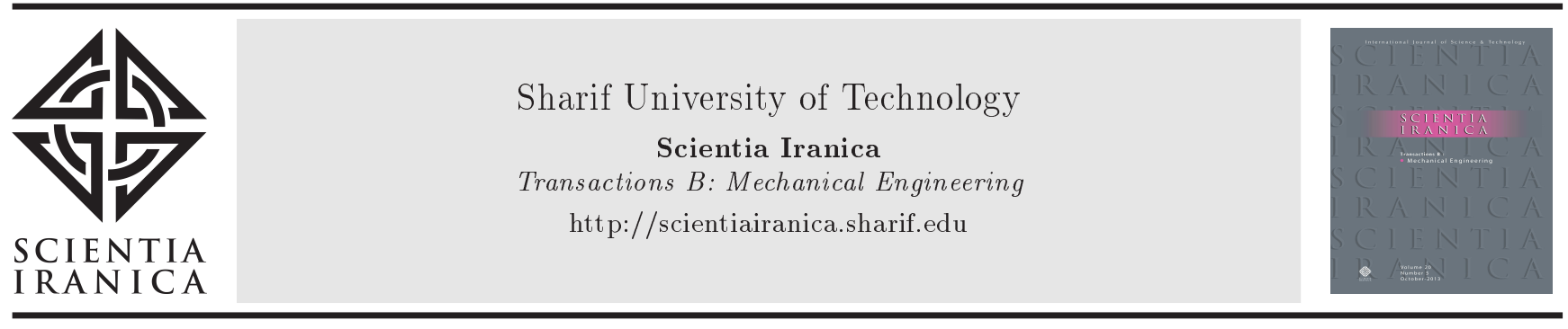

\title{
Numerical evaluation of the operating room ventilation performance: Ultra-Clean Ventilation (UCV) systems
}

\author{
B. Sajadi ${ }^{a}, *$ M.H. Saidi ${ }^{\text {, }}$, and G. Ahmadi ${ }^{c}$ \\ a. School of Mechanical Engineering, College of Engineering, University of Tehran, Tehran, Iran. \\ b. School of Mechanical Engineering, Sharif University of Technology, Tehran, Iran. \\ c. Department of Mechanical and Aeronautical Engineering, Clarkson University, Potsdam, NY.
}

Received 23 October 2017; received in revised form 24 March 2018; accepted 27 October 2018

KEYWORDS
Operating Room
(OR);
Ultra-Clean
Ventilation (UCV)
system;
Computational Fluid
Dynamics (CFD);
Surgical Site Infection
(SSI);
Surgical light.

\section{Introduction}

Surgical Site Infection (SSI) is one of the most important and potentially protectable causes of remedy duration increment and even death of the patients. According to the reports of the Center for Disease Control (CDC), SSI is the third most usual (14-16\%) nosocomial infection [1] and $2.6 \%$ of all surgeries lead to SSI [2]. It is obvious that the risk of SSI is greatly more during deep surgeries such as joint replacement. The additional cost of SSI approximated $\$ 2000$ per case

\footnotetext{
*. Corresponding author. Tel.: +982161119944 E-mail addresses: bsajadi@ut.ac.ir (B. Sajadi); saman@sharif.edu (M.H. Saidi); gahmadi@clarkson.edu (G. Ahmadi)
}

doi: $10.24200 /$ sci.2018.5431.1269 in 1980 [3], which rose to $\$ 5000$ in 1999 [2]. In addition to such a rapid growth rate, the digits show that SSI imposes direct cost of approximately $\$ 3.5$ billion per year on the US healthcare industry [4].

It is well known that the most common pathogen causing SSI is Staphylococcus aureus, which is responsible for $48 \%$ of all cases [2]. Staphylococcus aureus is a spherical bacterium naturally found in the normal human skin, of which the resultant infections have become more challenging in the recent decades with the recognition of several antibiotic-persistent strands of bacteria [4]. According to the literature, the primary source of Staphylococcus aureus is the flakes or squames, which are released from the exposed skin of surgical staff or patients [5]. These particles are $25 \mathrm{~m}$ in diameter and 3-5 $\mu \mathrm{m}$ in thickness. It is estimated that during two to four hours of surgery, 1.15 to 90 million flakes are released [6], among which typically 
$5-10 \%$ carry bacteria [7]. A surgeon, bending over a patient, may be a source of as many as 1000 airborne particles per minute [8] and closeness of the surgical staff to the operating table increases the risk of wound contamination in turn.

The risk of SSI depends on several factors, including patient (susceptibility to infection), staff (practices), operating room (cleanliness), and HVAC system (ACH and airflow pattern) [9]; their interaction is shown in Figure 1 more extensively [10]. Although health professionals have successfully used various techniques to prevent the surgical wound from infection, e.g., sterilizing, practicing on the staff, using antibiotics, and developing Minimum Invasive Surgery (MIS) methods, SSI still occurs. Woods et al. [5] categorized the sources of wound infection into (1) patient, (2) non-sterilized instruments, and (3) airborne bacteria. It is believed that the major number of SSI cases are due to airborne bacterial particles, which may be minimized using an optimum ventilation strategy. Application of an appropriate ventilation system is well known as the most effective way to control harmful microbiological agents responsible for SSI. The reason for this idea is that plausible evidences have shown considerable reduction in the number of postoperative SSIs after the application of cleanroom technology to operating rooms in 60s [11]. Field studies of Lidwell et al. [12], Charnley [13], and Ferrazzi et al. [14] on joint replacement, hip replacement, and cardiac surgeries, respectively, showed approximately $50 \%$ improvement in the wound infection control using a proper ventilation airflow pattern.

Classification of the operating room ventilation systems is almost the same as the cleanroom ones [15]: (1) conventional and (2) unidirectional or laminar. Laminar systems, which are also known as Ultra-Clean
Ventilation (UCV) systems, according to NHS [16], provide a protected area for both the patient and the surgical team. Using a UCV system, the airborne bacteria transmission from less clean to more clean areas becomes minimized. As a consequence, it is recommended that any surgical procedure which deals with subcutaneous tissues or internal organs be performed in an operating room equipped with such systems [17]. It is well recognized that a downward unidirectional flow provides the most effective airflow pattern in UCV systems [16]. However, this configuration has some disadvantages, the major one being that the flow may be easily disturbed by upstream obstacles, especially surgical lights [18]. As a result, some other configurations such as horizontal [19], diagonal [20], trumpet-shaped [4], exponential [21], and local [22] have also been presented during the years, which may be preferable to the vertical pattern in specific situations [23].

Since the early $90 \mathrm{~s}$, with considerable improvement in the computational capacity of computers, Computational Fluid Dynamics (CFD) techniques have become powerful tools for engineering design, including investigation into the Indoor Air Quality (IAQ) [24]. Generally, flow characteristics in an operating room depend on the supply inlets/return outlets configuration, the ventilation airflow rate, and the effect of obstacles such as surgical luminaries. It is generally agreed that the location of return outlets is not as important as that of the supply inlets [25-27]. Memarzadeh and Manning [9] suggested that using mixed high-low level outlets might lead to a better airflow distribution; however, the differences were not significant enough to make low-or high-level systems unreliable. Although supply inlets arrangement has a considerable effect on the airflow pattern and the Indoor Air Quality (IAQ) in

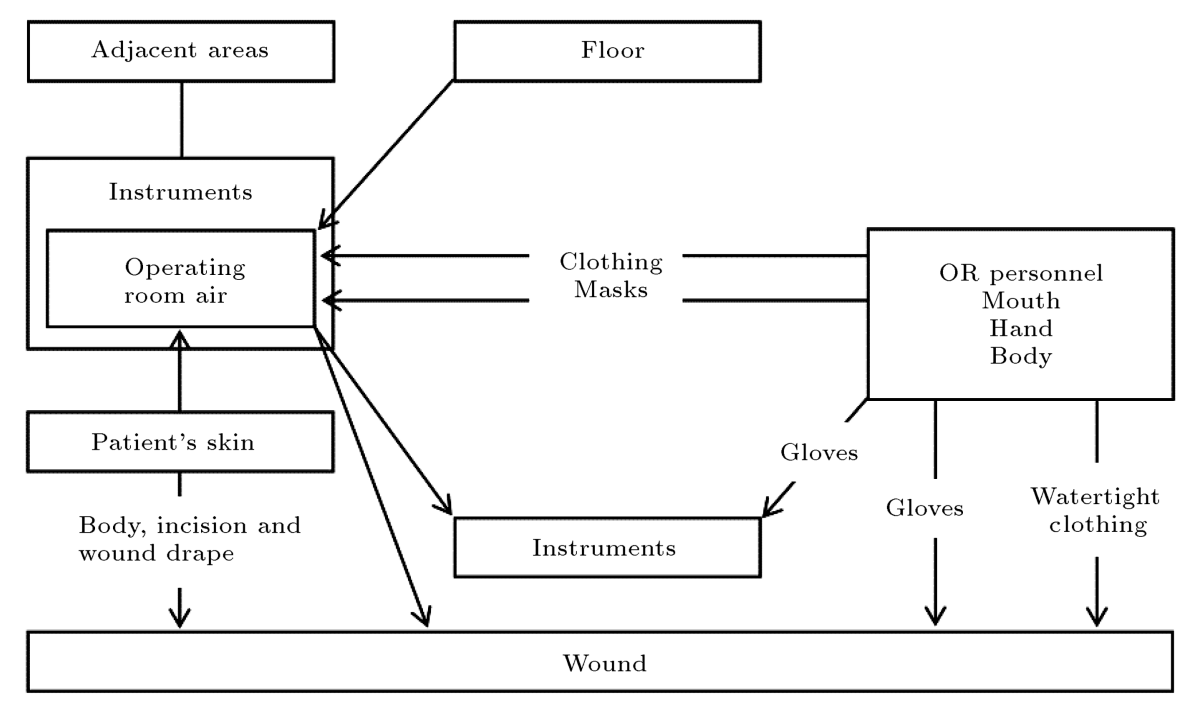

Figure 1. Interaction of the factors participating in the risk of SSI [10]. 
conventionally ventilated cleanrooms [26,27], it seems that there is no concern for this issue in a UCV system, provided that the unidirectional zone covers all the operating site and the surgical team. As one of the pioneers in this area, Chen et al. [25] investigated the contaminant concentration and the draught risk in an operating room through Eulerian-Eulerian numerical approach. They concluded that increasing the ventilation airflow rate would lead to a better air quality. Later, this conclusion was also reported by some other researchers [28]. It is noteworthy that this result is contrary to some experimental evidences proving that sometimes the ventilation airflow increment has no [29] or even negative effect [30] on the wound infection rate. It is believed that this inconsistency is mainly due to using Eulerian point of view in describing the transmission of bacterial particles. As mentioned previously, bacteria-carrying skin flakes are approximately $10 \mu \mathrm{m}$ in diameter. In this size, particles are not in hydrodynamic equilibrium with the airflow [31] and thus, Eulerian approach cannot reflect all the aspects of the behavior of particles. Memarzadeh and Manning [32] in National Institute of Health (NIH) conducted extensive numerical studies to investigate the effect of operating room ventilation system on reducing the risk of surgery. Using a Eulerian-Lagrangian code, they concluded that the indoor air pattern was more important than the airflow ventilation rate to prevent the wound from infection. They found that for laminar airflow systems, there was an optimum value for the inlet air velocity, namely $0.15 \mathrm{~m} / \mathrm{s}$, over which the particles deposition on the wound increased due to break of the protecting wound thermal plume [9]. Based on this result, which has also been stated by Rui et al. [33] and supported by the previous field studies $[29,30]$, although the ventilation airflow increment leads to less contaminant concentration in the operating room, it does not necessarily decrease wound infection. Despite the fact that the results of Memarzadeh and Manning [9] are the basis for ASHRAE recommendations [34], it seems that the optimum inlet air velocity is not thoroughly unique. They proposed the optimum velocity near $0.15 \mathrm{~m} / \mathrm{s}$, but other researchers have reported somehow different values $[15,33,35]$, which may be due to some discrepancies in other design parameters.

In addition to the flow pattern and the inlet air velocity, the previous research studies have shown that openings [36] and the configuration of internal obstacles may affect the indoor airflow in operating rooms. The main obstacles around a patient are surgical staff and operating luminaries, which may influence the infection risk. During the recent years, some studies have been performed, mainly by Sadrizadeh et al., to investigate the effect of the number of staff members [37], their clothing [38], their position [39], and their movement [40] on the airflow pattern and the dispersion of airborne particles in surgical theaters. Recently, Zoon [41] compared the effect of three operating lamp types on the flow field in a typical surgical room using the laminar flow index, numerically. However, they did not provide any clear recommendation regarding the effect of the light location, which may be as important as its type.

In this research, the airflow pattern in an operating room equipped with a UCV system is studied in detail and the effect of important factors, e.g., the operating lights boundary conditions, on the optimum inlet air velocity is evaluated. This investigation and its results are useful in getting a better understanding of the airflow pattern over the operating rooms and in developing more effective ventilation strategies.

\section{Numerical modeling}

\subsection{Geometry}

Figure 2 shows a schematic of the operating room model. It has an area of $37 \mathrm{~m}^{2}$, which is common around the world, including Iran [42]. Since the main geometric features of operating rooms are almost the same, far more or less, arrangement of the operating staff, the equipment, and the patient is done in accordance with DIN 4799 [43]. Due to the complex geometry of the model, a tetrahedral unstructured mesh is used to discretize the computational domain. The primary study shows that $1.8 \times 10^{6}$ cells are sufficient to guarantee the independency of the results from the number of grids and the mesh should be denser in the ultra-clean area, where the gradients are predicted to be higher.

\subsection{Governing equations}

For an incompressible flow, Reynolds-averaged governing equations are [44]:

Mass equation:

$$
u_{i, j}=0 \text {. }
$$

Momentum equation:

$$
\rho u_{j} u_{i, j}=-P_{, i}+\left(\mu u_{i, j}-\rho \overline{u_{i}^{\prime} u_{j}^{\prime}}\right)_{, j}+\rho g \beta\left(T-T_{\infty}\right) .
$$

Energy equation:

$$
\rho c_{p} u_{j} T_{, j}=\left(k T_{, j}-\rho c_{p} \overline{T^{\prime} u_{j}^{\prime}}\right)_{, j},
$$

where the buoyancy force is estimated using Boussinesq model and the viscous dissipation term is neglected in the energy equation. Reynolds stresses, $\rho \overline{u_{i}^{\prime} u_{j}^{\prime}}$, and Reynolds heat fluxes, $\rho c_{p} \overline{T^{\prime} u_{j}^{\prime}}$, rise from turbulent fluctuations and should be estimated through an appropriate turbulence model. Among many turbulence models, which have been presented through the years, 

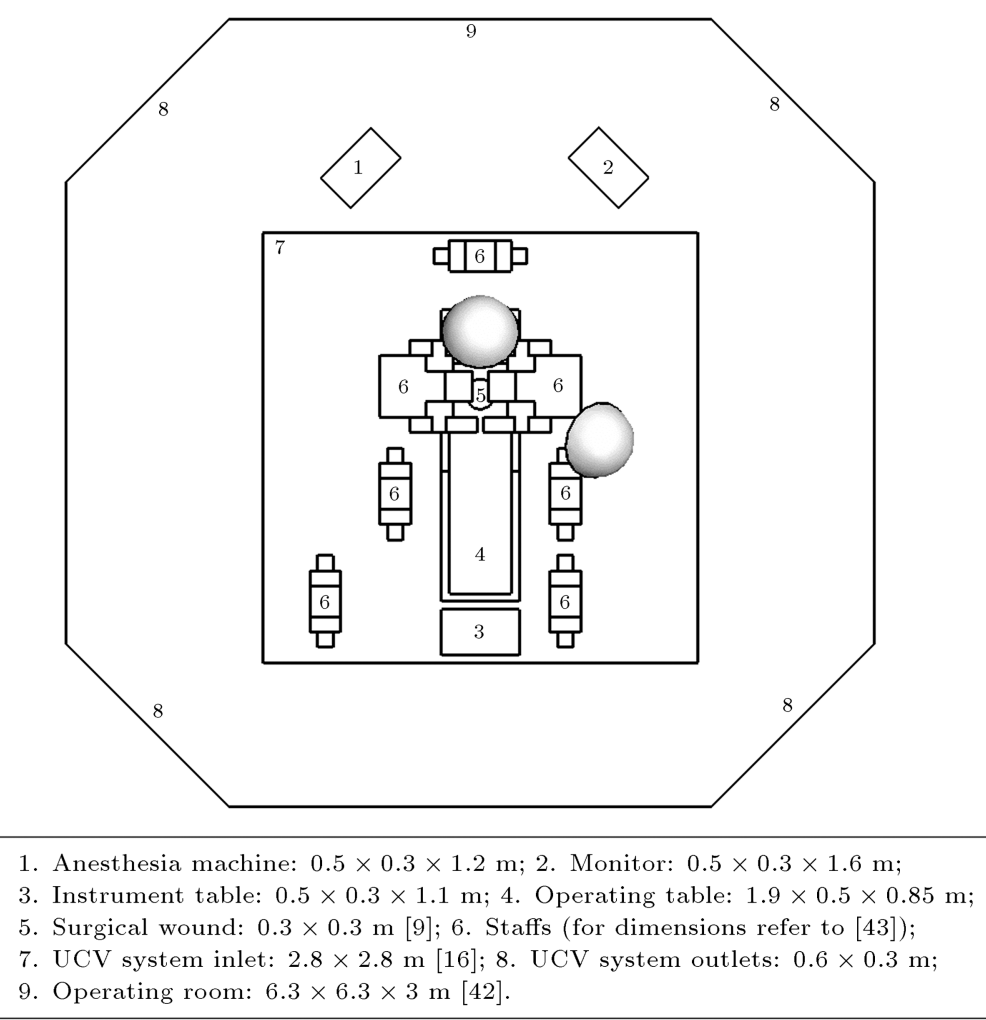

Figure 2. Geometric specifications of the operating room model. For standard distance refer to [43].

Boussinesq hypothesis-based $k$ - $\varepsilon$ family models are very popular for industrial applications due to their simplicity, stability, and acceptable results [44]. In the middle of the $90 \mathrm{~s}$, Chen [45] compared 5 most common $k-\varepsilon$ models and recommended RNG $k-\varepsilon$ one for simulating the indoor airflows, although the standard model also gave acceptable results. During the past decades, most of the researchers have used the standard $[9,46]$ or RNG $k-\varepsilon[46,47]$ model and few studies, which were conducted using other models [48-50], did not report a significant preference. In the present study, the momentum equations are closed using RNG $k-\varepsilon$ turbulence model and, as the model fails in the nearwall region, the standard wall function is implemented to resolve the problem [44]. The governing equations are solved on a collocated grid using ANSYS FLUENT 12.1 [51] as a solver. Pressure-velocity coupling is established through SIMPLE [52] algorithm and the convection terms are discretized using second-order upwind scheme, which has an acceptable accuracy in the indoor airflow modeling [53].

It is almost well known that the Eulerian-Eulerian approach is not suitable to study the motion of bacterial airborne particles due to their relatively large size [9]. Using Lagrangian approach, the particle motion equation becomes [54]:

$$
\frac{d u_{i}^{p}}{d t}=\frac{1}{\tau}\left(u_{i}-u_{i}^{p}\right)+g_{i}+n_{i}(t)
$$

where $g_{i}$ and $n_{i}$ are the gravity and Brownian forces, respectively, and $\tau$, the particle relaxation time, is defined as:

$$
\tau=\frac{S d_{p}^{2} C_{c}}{18 \nu},
$$

where $S$ is the particle to fluid density ratio and Cunningham slip correction factor, $C_{c}$, is implemented to compensate for the non-continuum effects:

$$
C_{c}=1+K_{n}\left[1.257+0.4 \exp \left(-\frac{1.1}{K n}\right)\right],
$$

where Knudsen number is:

$$
K_{n}=\frac{2 \lambda}{d_{p}},
$$

and $\lambda$ is the air mean free path, which equals $68 \mathrm{~nm}$ in the normal conditions. Other forces, such as Saffman's lift force, are negligible due to the relatively large size of the investigated particles.

As the turbulence diffusion is one of the most important features of the indoor airflow, its accurate estimation is necessary for predicting the particle trajectory. In this study, the Discrete Random Walk (DRW) model [51] is used, which simulates the turbulent fluctuating velocity components as:

$$
u_{i}^{\prime}=G \sqrt{\overline{u_{i}^{\prime 2}}},
$$


where $G$ is a white noise random number and $\sqrt{\overline{{u_{i}^{\prime 2}}^{2}}}$ is the Root Mean Square (RMS) of the fluctuating velocity components. For the $k-\varepsilon$ turbulence models, the RMS components are the same and equal to $2 / 3 k$.

To evaluate the appropriate time to update the random number $G$, the eddy lifetime and the particle crossing time concepts are used. The characteristic lifetime of the turbulent energy containing eddies is defined as a constant:

$$
\tau_{e}=2 T_{L},
$$

where $T_{L}$ is the turbulent Lagrangian time scale and for the $k-\varepsilon$ turbulence models, it can be estimated as:

$$
T_{L}=0.15 \frac{k}{\varepsilon}
$$

The particle eddy crossing time, that is, the time a particle needs to pass across an eddy, is defined as:

$$
\tau_{c}=-\tau \operatorname{In}\left(1-\frac{L_{e}}{\tau\left|u-u_{p}\right|}\right)
$$

where $L_{e}$ is the eddy length scale and for the $k-\varepsilon$ turbulence models, it can be approximated by:

$$
L_{e}=0.16 \frac{k^{3 / 2}}{\varepsilon} .
$$

The particle is assumed to interact with eddies over the smaller values of $\tau_{e}$ and $\tau_{c}$ [51]; thus, the random number, $G$, should be updated at this time.

\subsection{Boundary conditions}

The boundary condition at the UCV system inlet is constant velocity and constant temperature of $300 \mathrm{~K}$; also, all gradients are assumed to be zero at the outlets. While no slip boundary condition is almost always applied to the momentum equations for the walls, appropriate thermal boundary condition is one of the most important factors regarding heat source surfaces. As the power of heat sources is usually known, constant heat flux is the most common type of boundary condition on the walls. However, there are some issues that bring this choice into question. The total surface area of the modeled source, e.g., a human manikin, is usually considerably different from the real one. In addition, the thermal radiation heat transfer mechanism, e.g., in surgical lights, is usually neglected in the indoor airflow modeling. Both of the abovementioned simplifications lead to surface temperature in the source and cause the resultant thermal plume power to be far from the actual value. Accordingly, if there are some experimental results regarding the surface temperature of the heat sources, using constant temperature boundary conditions seems to be more realistic. In this investigation, constant temperature of $300 \mathrm{~K}[18,25]$ is used for the human (staff and patient) skin, except at the surgical wound, where the temperature equals $310 \mathrm{~K}$, i.e., the core body temperature [9]. In contrast to human skin, there is not much information about surface temperature of the surgical lights. However, some previous experimental studies [55] have shown that it is almost $350 \mathrm{~K}$; this value is used for the basic simulation and the effect of the surgical luminary thermal boundary condition on the results is discussed separately.

The behavior of the particles on the boundaries is also important for the particle trajectory. As emphasized by Tian et al. [55] through comparison between experimental and LES numerical results, the particles tend to deposit on the floor, but they usually rebound onto a vertical wall or a ceiling. This behavior has a considerable effect on the final deposition rate of the airborne particles. As a particle reaches the outlets, it is assumed that it exits the computational domain.

\subsection{Validation}

To validate the implemented numerical method, the benchmark of Posner et al. [56], which is widely accepted for the validation of the research work on indoor airflow modeling [57], has been used. As shown in Figure 3, the geometry is a room of $91.4 \mathrm{~cm}$ length, $45.7 \mathrm{~cm}$ width, and $30.5 \mathrm{~cm}$ height. A partition with the length of $45.7 \mathrm{~cm}$ and height of $15.25 \mathrm{~cm}$ divides the room into two equal parts. The air is supplied with the velocity of $0.235 \mathrm{~m} / \mathrm{s}$ from a $10.1 \times 10.1 \mathrm{~cm}^{2}$ inlet grill at the ceiling of one of the room parts and it exits through a similar outlet grill at the ceiling of the other part. In Figure 4, the numerical results of the $y$ velocity along line $\mathrm{A}$ and the $x$-velocity along line $\mathrm{B}$ are compared with the experimental data [56]. According to the results, the present model may predict the indoor airflow with reasonably good accuracy.

\section{Results and discussion}

The most important specification of UCV systems is the ventilation airflow inlet velocity. As mentioned pre-

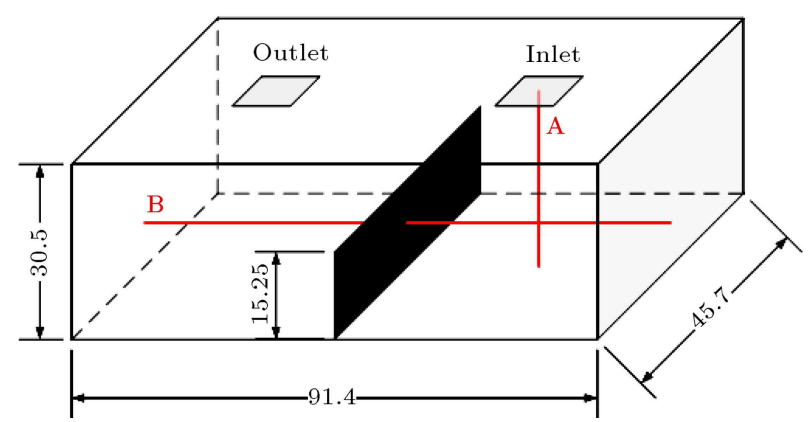

Figure 3. Geometric specifications of the validation model [56] (dimensions are in millimeters). 


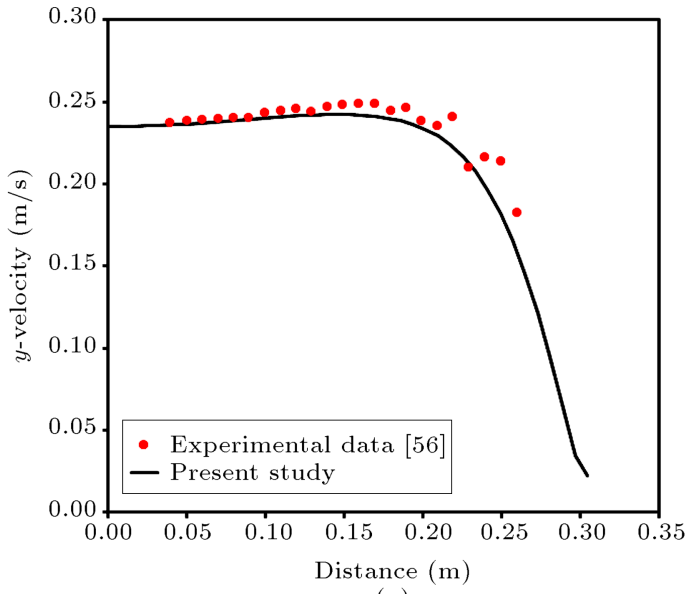

(a)

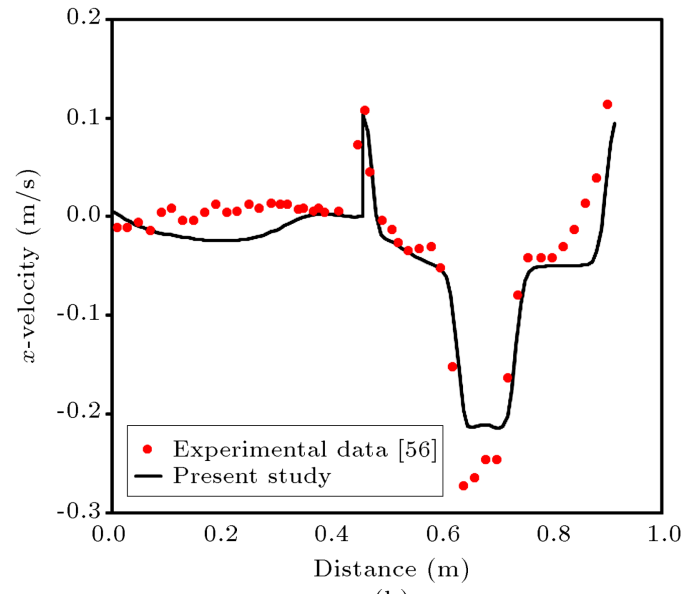

(b)

Figure 4. Comparison of the simulation results with the experimental data [56]: (a) y-velocity along line A and (b) $x$-velocity along line B.

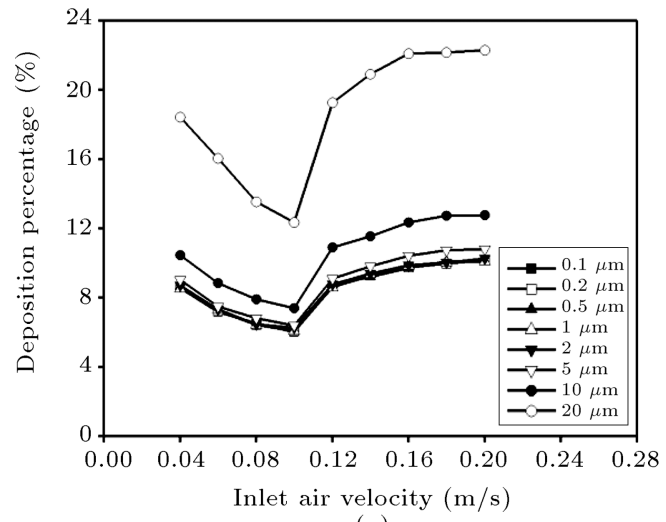

(a)

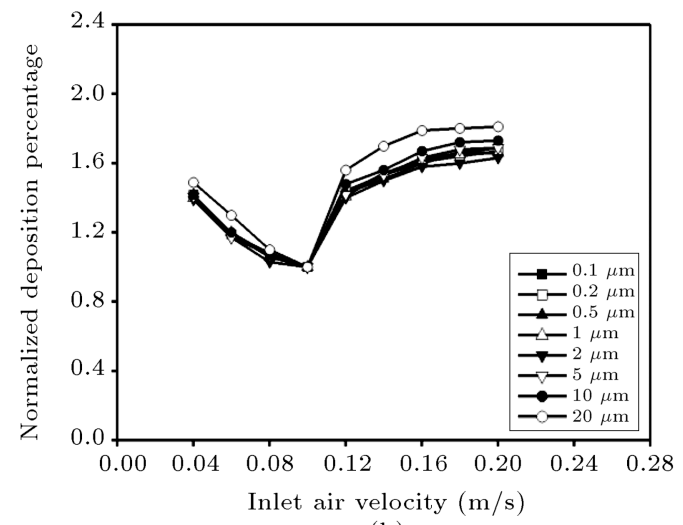

(b)

Figure 5. Effect of ventilation airflow inlet velocity and particle size on the particles deposition: (a) Deposition percentage and (b) normalized deposition percentage.

viously, there is no unique agreement in the literature on the optimum value and it, more or less, depends on geometry of the room. In 2003, Memarzadeh and Manning [9] found that only particles released close to the wound may lead to its contamination. As a result, although some experimental evidences are needed, it seems that the contaminant source location is not as important as other parameters in an operating room equipped with a UCV system. To study the effect of design parameters on the wound contamination, particles released uniformly from $0.01 \mathrm{~m}^{3}$ volume over the wound and the percentage of particles deposition on the wound are evaluated. The particle specifications are assumed to be similar to water, as bio-aerosols are mostly made of water. The primary study shows that $10^{5}$ particles are necessary to ensure that the percentage of deposited particles becomes independent of the number of released particles.

Figure 5(a) shows the effect of the inlet air velocity and the size of particles on the percentage of deposited particles. As depicted in the figure, the particles deposition is almost independent of the particle size in the range of $0.1-1.0 \mu \mathrm{m}$ and increases rapidly over $1.0 \mu \mathrm{m}$ due to gravitational sedimentation. As the Stokes' number of particles is relatively small, the impaction effect has no meaningful contribution to their deposition. In addition, due to relatively large size of particles, Brownian motion is negligible and the main deposition mechanisms are only turbulence diffusion and gravitational sedimentation. Sedimentation effects vanish rapidly as the particle size goes below $1.0 \mu \mathrm{m}$ and the deposition curves become almost the same, as the turbulence diffusion is independent of the particle size. The main feature of the deposition curves in Figure 5(a) is that all show an optimum value for the inlet velocity to minimize the deposition of particles. As an interesting result, the optimum inlet velocity is independent of the particle size. To better evaluate the optimum value, the particles deposition curves can be normalized based on the minimum deposition percentage, as shown in Figure 5(b). The existence of such an optimum value is due to the formation 


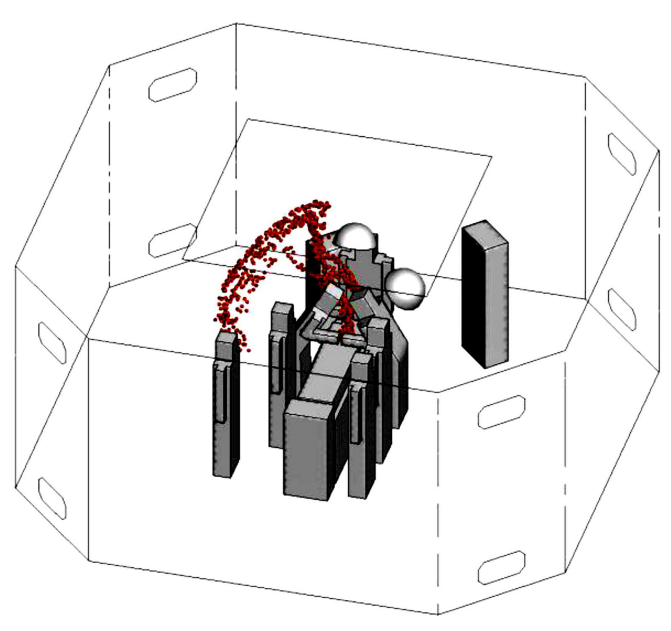

(a)

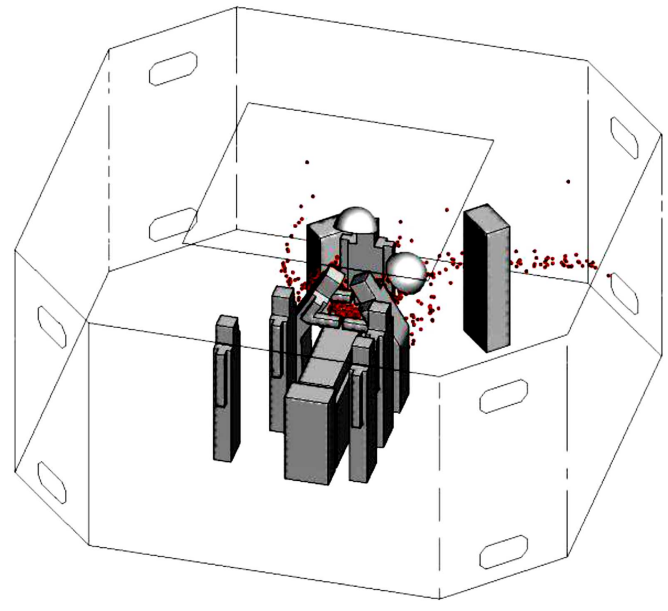

(b)

Figure 6. Effect of ventilation inlet air velocity on the dispersion of $10 \mu \mathrm{m}$ particles after 60 seconds: (a) $0.1 \mathrm{~m} / \mathrm{s}$ and (b) $0.2 \mathrm{~m} / \mathrm{s}$.

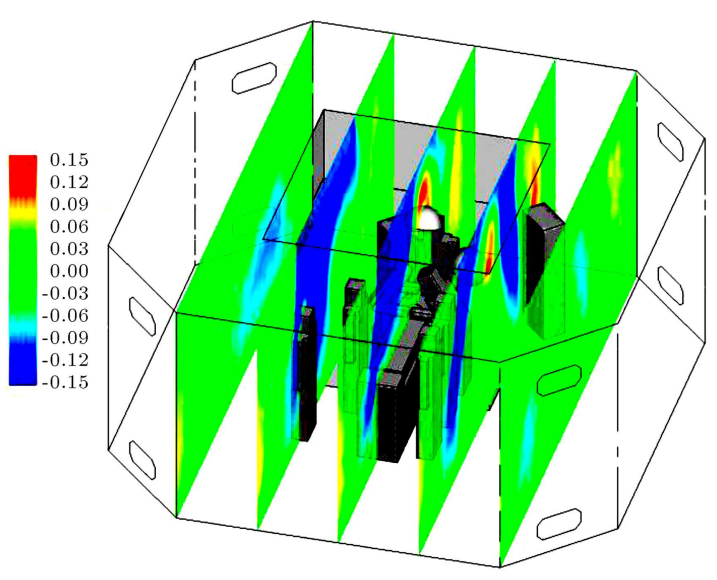

(a)

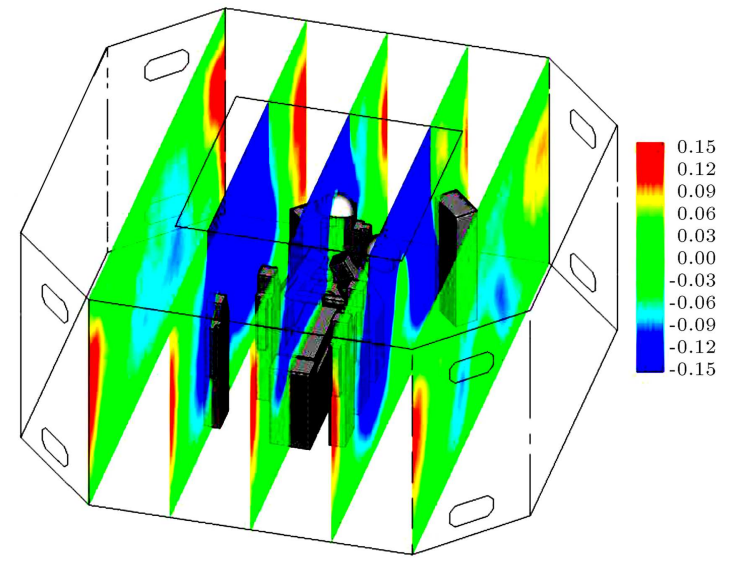

(b)

Figure 7. Effect of inlet air velocity on the $z$-velocity contours in the operating room: (a) $0.1 \mathrm{~m} / \mathrm{s}$ and (b) $0.2 \mathrm{~m} / \mathrm{s}$.

of a thermal plume over the wound, which acts as a protecting shield at low velocities and may be disturbed when the ventilation airflow inlet velocity goes beyond an optimum value. As mentioned previously, turbulent diffusion is the main mechanism to deposit the contaminant particles on the wound. The turbulence diffusion depends not only on the particle concentration, but also on the average turbulence intensity over the wound. Consequently, the ventilation airflow should be sufficiently high to remove the particles form the wound and reduce the particle concentration on it. At the same time, it should not be too high to destroy the protecting wound thermal plume and increase the turbulence intensity level over the wound. Such behavior of the operating room indoor airflow leads to the existence of an optimum value for the ventilation air inlet velocity.

The dispersion of $10 \mu \mathrm{m}$ particles after 60 seconds is illustrated at Figure 6(a) and (b) for the inlet air velocities of $0.1 \mathrm{~m} / \mathrm{s}$ and $0.2 \mathrm{~m} / \mathrm{s}$, respectively. In addition, Figure $7(\mathrm{a})$ and (b) depict the $z$-velocity contours for the operating room. As it is clear in the figures, increase in the inlet velocity beyond the optimum value disturbs the wound thermal plume and increases unfavorable particles deposition, accordingly. The thermal plume, which is generated by the temperature difference between the wound tissue and the body skin, forms an upward flow over the wound and protects it from contaminant airborne particles. Beyond the optimum inlet velocity, the shielding thermal wound breaks down and the particles deposition increases, accordingly, as the released particles may be pushed to the wound due to the high level of turbulence intensity.

To describe the role of the shielding thermal plume in protecting the wound from contaminants more extensively, an evident case is investigated in which the wound thermal plume has been removed using $300 \mathrm{~K}$ as the wound temperature. The particles deposition curves of the evident case are compared 


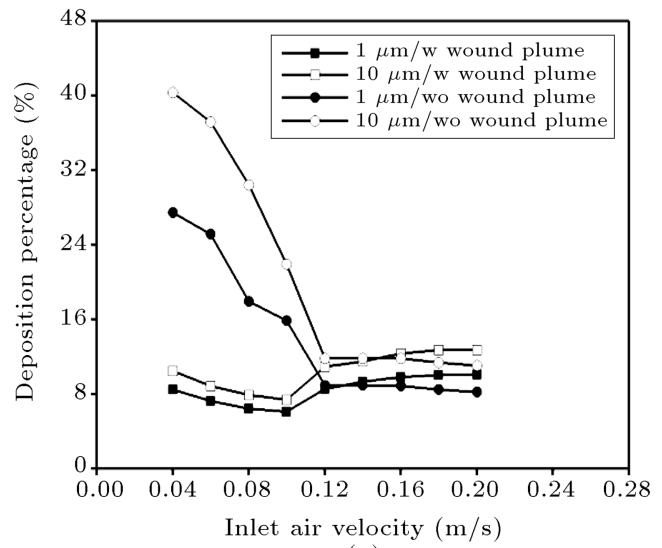

(a)

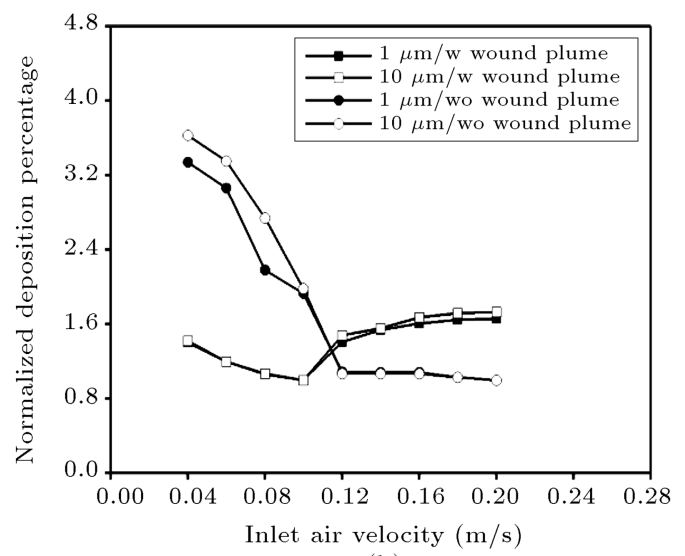

(b)

Figure 8. Effect of the wound thermal plume on the particles deposition: (a) Deposition percentage and (b) normalized deposition percentage.

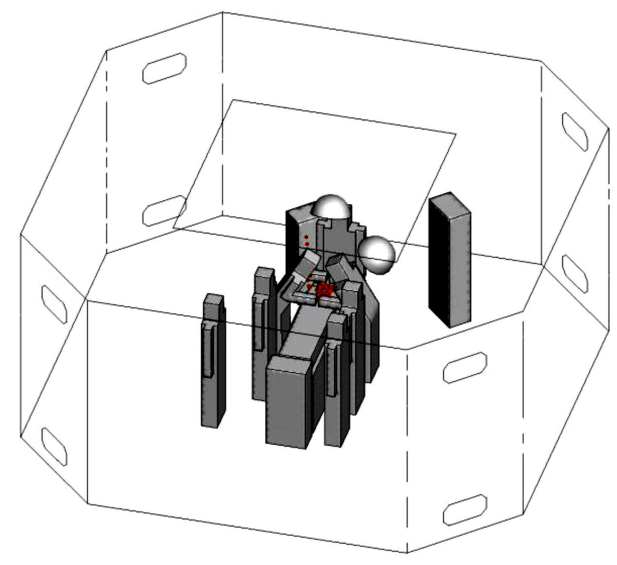

(a)

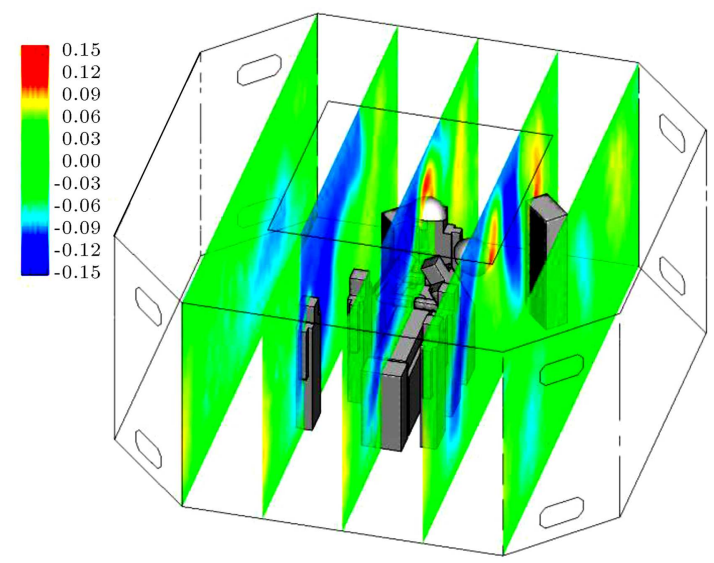

(b)

Figure 9. Indoor airflow specifications in a case without thermal plume at $0.1 \mathrm{~m} / \mathrm{s}$ inlet air velocity: (a) Dispersion of $10 \mu \mathrm{m}$ particles after 60 seconds and (b) z-velocity contours in the operating room.

with the basic one in Figure 8. Based on the figure, the existence of an optimum value for the inlet air velocity is a direct consequence of the thermal plume formation over the wound. As depicted in Figure 8, without any temperature difference between the wound tissue and the body skin, there is no optimum value for the inlet air velocity and the ventilation system performance shows a continuous improvement as the inlet air velocity increases. The effect of the wound thermal plume is more sensible at low inlet air velocity when it acts as a shield to protect the wound from contaminant particles. At high inlet air velocity, the thermal plume breaks down and the results are almost the same in both cases. The effect of the wound thermal plume may be found out better via the comparison of Figure 9(a) and (b) with Figures 6 and 7, respectively. As shown in the figures, the thermal plume directs the particles outwards the wound and protects it from deposition of bacteria-carrying flakes.

As discussed previously, UCV systems usually use a downward airflow pattern. As a result, the downstream obstacles may influence the optimum inlet air velocity and the resultant indoor airflow distribution. It is well known that operating lights, as the main downstream obstacles in operating rooms, have a considerable negative effect on the ventilation airflow pattern due to both hydrodynamic obstruction effect and generation of a thermal plume. Although the hydrodynamic obstruction of a light depends only on its geometry and is almost fixed, the power of the generated thermal plume is completely coupled with the light surface thermal boundary condition. It is very common to use a constant heat flux boundary condition for the operating lights based on their power consumption. However, as mentioned previously in the section on boundary conditions, most of the power used by the lights is transmitted via radiation mechanism, which is not normally considered in the indoor airflow investigations. Such a simplification in the heat transfer mechanisms modeling leads to over-prediction 


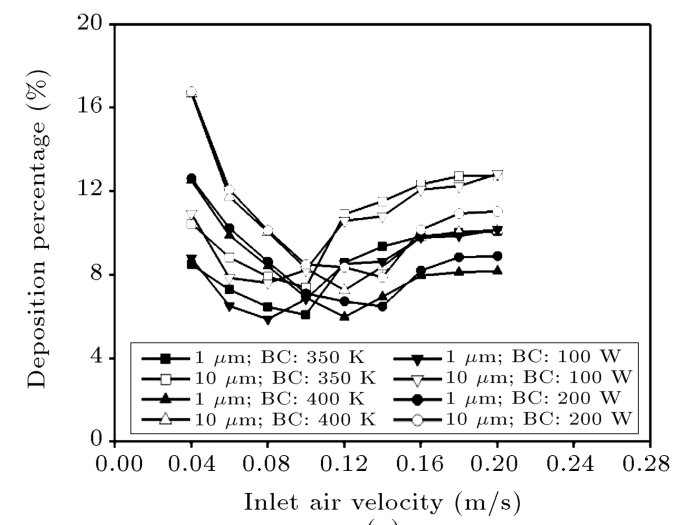

(a)

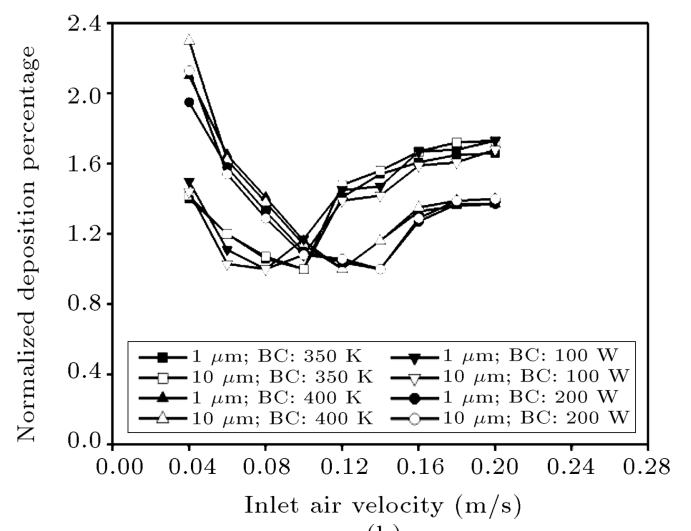

(b)

Figure 10. Effect of the operating luminary boundary condition on the particles deposition: (a) Deposition percentage and (b) normalized deposition percentage.

of the luminary surface temperature and the resultant thermal plume.

Luscuere et al. [58] pointed out that the flow disturbance due to thermal plumes of the lights was not as important as their obstruction effect. However, Tinker and Robert [59], via CFD modeling, found out that the effect of the thermal plumes was thoroughly dispersed only when the inlet air velocity was over $0.3 \mathrm{~m} / \mathrm{s}$. This trend was also supported quantitatively by the numerical work of Chow and Yang [18,28]. As the optimum inlet air velocity is considerably lower than $0.3 \mathrm{~m} / \mathrm{s}$, the effect of the thermal plumes of the operating lights on the operating room indoor airflow pattern and the resultant wound contamination may still be considerable.

In Figure 10, the effect of the luminary boundary condition on the particles deposition is illustrated for two constant temperature boundary conditions, namely $350 \mathrm{~K}$ and $400 \mathrm{~K}$, and two constant heat flux boundary conditions, namely $100 \mathrm{~W}$ and $200 \mathrm{~W}$. As depicted in the figure, the operating lights boundary condition has a considerable effect on the particles deposition curve, both on the deposition values and on the optimum inlet air velocity. The negative effect of the thermal plumes generated over the luminaries is such strong that it can increase the optimum inlet air velocity up to $0.14 \mathrm{~m} / \mathrm{s}$. The effect of the surgical lights thermal plume may better be understood by looking at Figure 11, in which the thermal plume power is illustrated by $z$-velocity iso-surfaces. As depicted in the figure, the plume causes an upward flow over the light, which may disturb the airflow pattern. To achieve the best performance, the inlet airflow should have enough momentum to overcome the upward flow of plumes. As a consequence, the case in Figure 11(d), which has the most powerful thermal plume, requires the highest optimum inlet air velocity, namely $0.14 \mathrm{~m} / \mathrm{s}$.

Another upstream obstacle, which may be found in an operating room, is the ultra-clean area partitions.

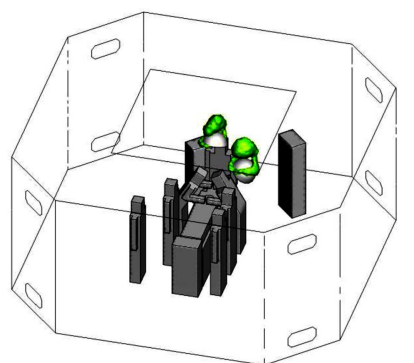

(a)

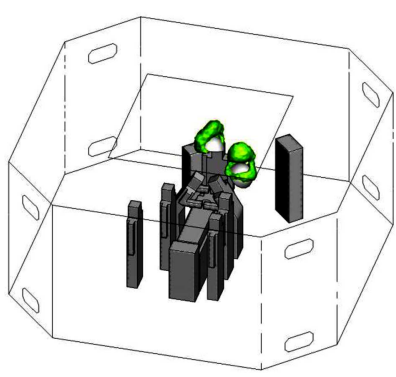

(c)

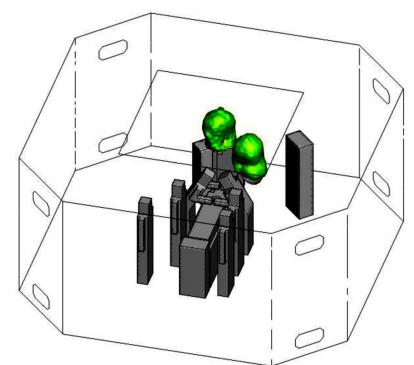

(b)

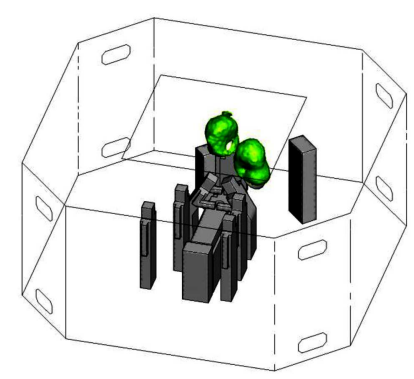

(d)
Figure 11. $+0.1 \mathrm{~m} / \mathrm{s} z$-velocity iso-surfaces at $0.1 \mathrm{~m} / \mathrm{s}$ inlet air velocity: (a) $350 \mathrm{~K}$, (b) $400 \mathrm{~K}$, (c) $100 \mathrm{~W}$, and (d) $200 \mathrm{~W}$.

The fixed and the removable partitions have been proposed by NHS [16] as a solution to improving the UCV system air quality; however, their effectiveness has not been evaluated yet in detail. As shown in Figure 2, the fixed and the removable partitions are $1 \mathrm{~m}$ in height and mounted on the ceiling, one after another, to protect the ultra-clean surgical area. The fixed partitions may be installed in the operating room as built, whereas the removable ones are only applicable after the surgical team settles down in the operating ultra-clean area. The effect of the partitions on the particles deposition percentage is illustrated in Figure 12. As shown in the figure, using the fixed partition reduces the number of deposited particles, while it has no effect on the optimum ventilation airflow 

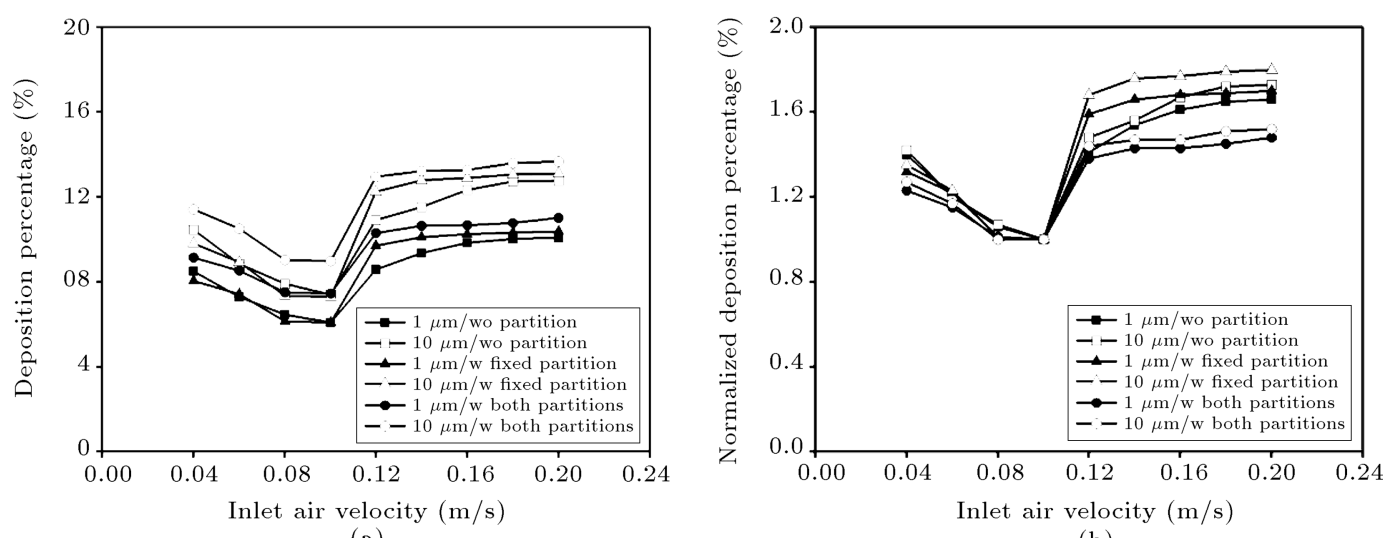

(a)

(b)

Figure 12. Effect of using fixed and removable partitions on the particles deposition: (a) Deposition percentage and (b) normalized deposition percentage.

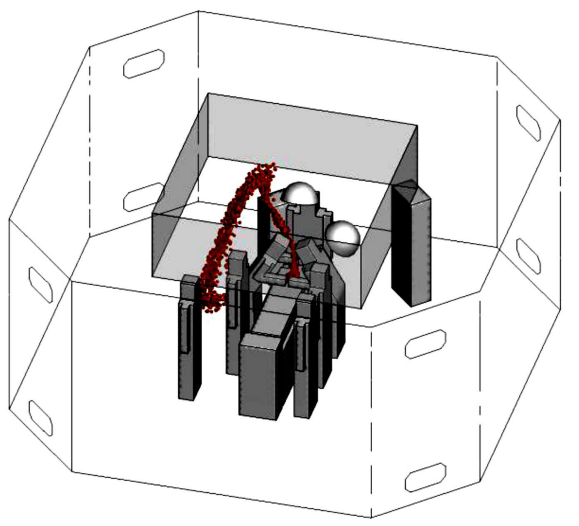

(a)

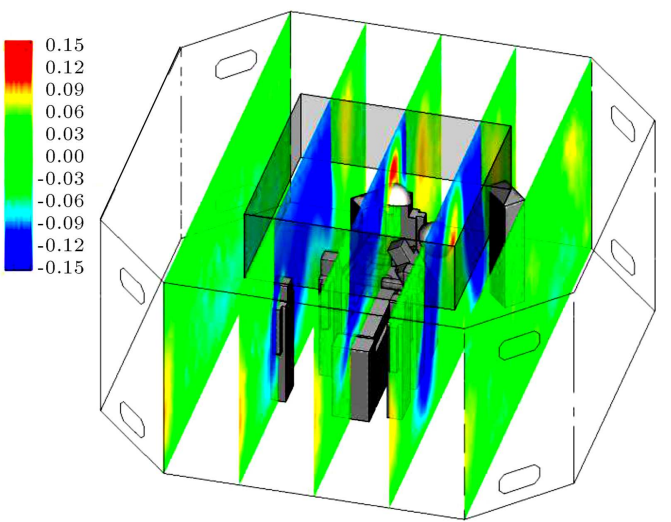

(b)

Figure 13. Indoor airflow specifications in a case with the fixed partition at $0.1 \mathrm{~m} / \mathrm{s}$ inlet air velocity: (a) Dispersion of $10 \mu \mathrm{m}$ particles after 60 seconds and (b) z-velocity contours in the operating room.

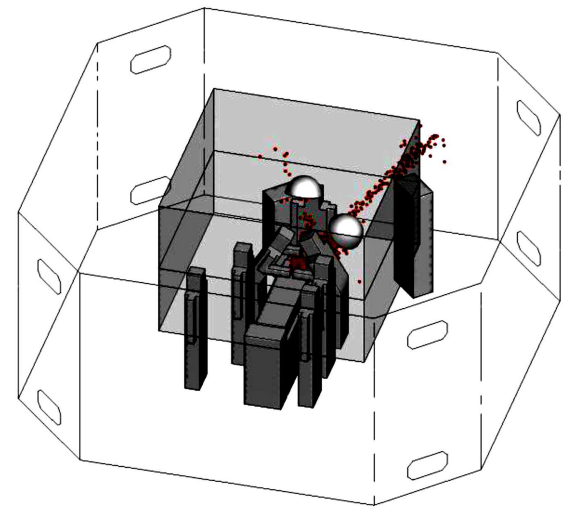

(a)

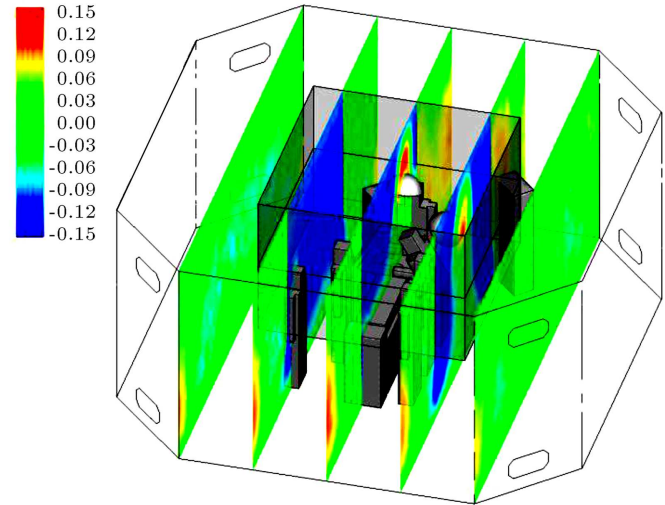

(b)

Figure 14. Indoor airflow specifications in a case with both partitions at $0.1 \mathrm{~m} / \mathrm{s}$ inlet air velocity: (a) Dispersion of 10 $\mu \mathrm{m}$ particles after 60 seconds and (b) z-velocity contours in the operating room.

rate. In contrary, using the removable one may even lead to increase in the particles deposition rate, which throws its usefulness into question.

The effect of partitions on the airflow pattern and the resultant particles deposition may better be understood by referring to Figures 13 and 14 . As depicted in the figures, the main effect of the partitions installation is to direct the ventilation airflow toward the surgical table and to prevent its momentum from decay due to expansion. However, this effect is not 
strong enough to change the optimum inlet air velocity. In addition, using the removable partition causes the inlet ventilation airflow to reach the wound with little changes and to disturb its protecting thermal plume, as shown in Figure 14(a). As a result, airborne particles deposition and wound infection increase in turn by higher turbulence diffusion. As illustrated in Figure 13(a), using the fixed partition pushes the released particles outward the wound by the thermal plume and the dispersion of particles becomes more regular than the basic case depicted in Figure 6(a). By adding the removable one, an extra momentum imposed by the airflow on the thermal plume makes it break down and disperse the released particles, as shown in Figure 14(a).

\section{Conclusions}

In this research, the effect of UCV system parameters on the ventilation performance and the risk of wound infection was investigated, numerically. The results may be summarized as follows:

1. Due to a relatively small Stokes' number and large size of the studied particles, the contribution of the inertial impaction and Brownian diffusion to the particles deposition was almost negligible. Accordingly, the main deposition mechanisms were turbulence diffusion and gravitational sedimentation. However, the effect of the latter rapidly vanished as the particle size went below $1.0 \mu \mathrm{m}$. It can be concluded that if the deposition percentage of different particle sizes becomes normalized based on the minimum value, all deposition curves will be almost the same;

2. The formation of a thermal plume over the wound, due to temperature difference between the wound tissue and the body skin, led to an optimum value for the inlet air velocity, which minimized the particles deposition. Over the optimum inlet velocity, the protecting thermal plume was destroyed and the particles deposition increased because of the high level of turbulence intensity near the wound;

3. The boundary condition of the operating luminaries had a considerable effect on the optimum inlet air velocity. Although the constant heat flux is the most common type of boundary condition for the indoor heat sources, it may lead to an overestimated surface temperature and thermal plume power by simplifying the geometries and/or neglecting the radiation heat transfer mechanism. According to the results of this study, using different boundary conditions for the operating lights may change the optimum inlet velocity in a relatively vast range from 0.1 to $0.14 \mathrm{~m} / \mathrm{s}$;
4. Although using fixed partitions in a UCV system decreases the particles deposition on the wound and the resultant infection risk, it has no meaningful effect on the optimum inlet air velocity. In addition, the installation of removable partitions showed a negative effect on the ultra-clean air quality by increase in the turbulence intensity level near the wound. As a result, it seems that the removable partitions should be used cautiously; however, more experimental and numerical research is needed in this area.

\section{Acknowledgement}

The financial support of this research, provided by Iran National Foundation Society (INFS), is greatly appreciated.

\section{References}

1. Malone, D.L., Genuit, T., Tracy, J.K., Gannon, C., and Napolitano, L.M. "Surgical site infections: reanalysis of risk factors", Journal of Surgical Research, 103, pp. 89-95 (2002).

2. Kirkland, K., Briggs, J.P., Trivette, S.L., Wilkinson, W.E., and Sexton, D.J. "The impact of surgical-site infections in the 1990s: attributable mortality, excess length of hospitalization, and extra costs", Infection Control and Hospital Epidemiology, 20, pp. 725-730 (1999).

3. Mangram, A.J., Horan, T.C., Pearson, M.L., Silver, L.C., and Jarvis, W.R. "Guideline for prevention of surgical site infection", Infection Control and Hospital Epidemiology, 20, pp. 247-278 (1999).

4. Stevenson, T.C. "Experimental investigation of hospital operating room air distribution", M.Sc. Thesis, Georgia Institute of Technology, Atlanta, GA (2008).

5. Woods, J.E., Brayman, D., Rasmussen, R.W., and Montag, G.M. "Ventilation requirements in hospital operating rooms - Part I: Control of airborne particles", ASHRAE Transactions, 92, pp. 396-426 (1996).

6. Goldman, M. "Operating room airflow and distribution", ASHRAE Winter Meeting, Dallas, TX (2000).

7. Noble, W.C. "Dispersal of bacteria from human skin", International Symposium on Contamination Control, Copenhagen, Denmark (1976).

8. Zamuner, N., ASHRAE Technical Data Bulletin: Hospital and Operating Room Ventilation, ASHRAE, Atlanta, GA (1986).

9. Memarzadeh, F. and Manning, A. "Reducing risks of surgery", ASHRAE Journal, 45, pp. 28-33 (2003).

10. Lewis, J.R. "Operating room air distribution effectiveness", ASHRAE Transactions, 99, pp. 1191-1199 (1993).

11. Turner, R.S. "Laminar air flow", Journal of Bone and Joint Surgery, 56, pp. 430-435 (1974). 
12. Lidwell, O.M., Elson, R.A., Lowbury, E.J., Whyte, W., Blowers, R., Stanley, S.J., and Lowe, D. "Ultra clean air and antibiotics for prevention of postoperative infection: A multi-center study of 8052 joint replacement operations", Acta Orthopaedica Scandinavica, 58, pp. 4-13 (1987).

13. Charnley, J. "Postoperative infection after total hip replacement with special reference to air contamination in the operating room", Clinical Orthopedics, 87, pp. 167-187 (1972).

14. Ferrazzi, P., Allen, R., Crupi, G., Reyes, I., Parenzan, L., and Maisonnet, M. "Reduction of infection after cardiac surgery: A clinical trial", Annuals of Thoracic Surgery, 42, pp. 321-325 (1986).

15. Whyte, W., Cleanroom Technology, John Wiley \& Sons, Chichester, UK (2001).

16. Health Technical Memorandum (2025): Ventilation in Healthcare Premises, National Health Service (NHS) Estates, London, UK (1994).

17. Humphreys, H., Stacey, A.R., and Taylor, E.W. "Survey of operating theatres in Great Britain and Ireland", Journal of Hospital Infection, 30, pp. 245252 (1995).

18. Chow, T.T. and Yang, X.Y. "Performance of ventilation system in a non-standard operating room", Building and Environment, 38, pp. 1401-1411 (2003).

19. Liu, J., Wang, H., and Wen, W. "Numerical simulation on a horizontal airflow for airborne particles control in hospital operating room", Building and Environment, 44, pp. 2284-2289 (2009).

20. Woloszyn, M., Virgone, J., and Stephane, M. "Diagonal air distribution system for operating rooms experiment and modeling", Building and Environment, 39, pp. 1171-1178 (2004).

21. Sadrizadeh, S. and Holmberg, S. "Effect of a portable ultra-clean exponential airflow unit on the particle distribution in an operating room", Particuology, 18, pp. $170-178$ (2015).

22. Loomans, M.G.L.C., de Visser, I.M., Loogman, J.G.H., and Kort, H.S.M. "Alternative ventilation system for operating theaters: Parameter study and full-scale assessment of the performance of a local ventilation system", Building and Environment, 102, pp. 26-38 (2016).

23. Sadrizadeh, S., Holmberg, S., and Tammelin, A. "A numerical investigation of vertical and horizontal laminar airflow ventilation in an operating room", Building and Environment, 82, pp. 517-525 (2014).

24. Chen, Q. and Jiang, Q.Z. "Significant questions in predicting room air motion", ASHRAE Transactions, 98, pp. 929-939 (1992).

25. Chen, Q., Zhai, J., and Moser, A. "Control of airborne particle concentration and draught risk in an operating room", Indoor Air, 2, pp. 154-167 (1992).

26. Murakami, S., Kato, S., and Suyama, Y. "Numerical and experimental study on turbulence diffusion fields in conventional clean rooms", ASHRAE Transactions, 94, pp. 469-493 (1988).

27. Murakami, S., Kato, S., and Suyama, Y. "Numerical study of diffusion field as affected by arrangement of supply and exhaust openings in conventional flow type clean room", ASHRAE Transactions, 95, pp. 113-127 (1989).

28. Chow, T.T. and Yang, X.Y. "Ventilation performance in the operating theatre against airborne infection: Numerical study on an ultra-clean system", Journal of Hospital Infection, 59, pp. 138-147 (2005).

29. Humphreys, H. and Taylor, E.W. "Operating theatre ventilation standards and the risk of postoperative infection", Journal of Hospital Infection, 50, pp. 8590 (2002).

30. Salvati, E.A. "Infection rates after 3,175 total hip and total knee replacements performed with and without a horizontal unidirectional filtered airflow system", Journal of Bone and Joint Surgery, 64, pp. 525-535 (1982).

31. Hinds, W.C., Aerosol Technology, John Wiley \& Sons, Chichester, UK (1999).

32. Memarzadeh, F. and Manning, A. "Comparison of operating room ventilation systems in the protection of the surgical site", ASHRAE Transactions, 108, pp. 3-5 (2002).

33. Rui, Z., Guangnei, T., and Jihong, L. "Study on biological contaminant control strategies under different ventilation models in hospital operating room", Building and Environment, 43, pp. 793-803 (2008).

34. HVAC Design Manual for Hospitals and Clinics, ASHRAE, Atlanta, GA (2003).

35. "Guidelines for design and construction of hospitals and health care facilities", AIA, Washington, DC (2006).

36. Sadrizadeh, S., Pantelic, J., Sherman, M., Clark, J., and Abouali, O. "Airborne particle dispersion to an operating room environment during sliding and hinged door opening", Journal of Infection and Public Health, 11(5), pp. 631-635 (2018). https://doi.org/10.1016/j.jiph.2018.02.007

37. Sadrizadeh, S., Tammelin, A., Ekolind, P., and Holmberg, S. "Influence of staff number and internal constellation on surgical site infection in an operating room", Particuology, 13, pp. 42-51 (2014).

38. Sadrizadeh, S. and Holmberg, S. "Surgical clothing systems in laminar airflow operating room: a numerical assessment", Journal of Infection and Public Health, 7, pp. 508-516 (2014).

39. Sadrizadeh, S., Afshari. A., Karimipanah, T., Hakansson, U., and Nielsen, P.V. "Numerical simulation of the impact of surgeon posture on airborne particle distribution in a turbulent mixing operating theatre", Building and Environment, 110, pp. 140-147 (2016).

40. Chow, T.T. and Wang, J. "Dynamic simulation on impact of surgeon bending movement on bacteriacarrying particles distribution in operating theatre", Building and Environment, 57, pp. 68-80 (2012). 
41. Zoon, W.A.C. "On the applicability of the laminar flow index when selecting surgical lighting", Building and Environment, 45, pp. 1976-1983 (2010).

42. MPROG 28\%: Healthcare Facilities - Guidelines for Mechanical Installations, MPROG, Tehran, Iran (2006).

43. DIN 4799: Heating, Ventilation and Air ConditioningTesting of Air Distribution Systems Serving Operating Theatres, DIN, Berlin, Germany (1990).

44. Chen, C.J. and Jaw, S.Y., Fundamentals of Turbulence Modeling, Taylor \& Francis, Washington, DC (1998).

45. Chen, Q. "Comparison of different $k-\varepsilon$ models for indoor airflow computations", Numerical Heat Transfer: Part B, 28, pp. 353-369 (1995).

46. Tian, Z.F., Tu, J.Y., Yeoh, G.H, and Yuen, R.K.K. "On the numerical study of contaminant particle concentration in indoor airflow", Building and Environment, 41, pp. 1504-1514 (2006).

47. Mendez, C., San Jose, J.F., Villafruela, J.M., and Castro, F. "Optimization of a hospital room by means of CFD for more efficient ventilation", Energy and Buildings, 40, pp. 849-854 (2008).

48. Chen, Q. "Prediction of room air motion by Reynoldsstress models", Building and Environment, 31, pp. 233-244 (1996).

49. Costa, J.J., Oliveira, L.A., and Blay, D. "Test of several versions for the $k-\varepsilon$ type turbulence modeling of internal mixed convection flows", International Journal of Heat and Mass Transfer, 42, pp. 4391-4409 (1999).

50. Stamou, A. and Katsiris, I. "Verification of a CFD model for indoor airflow and heat transfer", Building and Environment, 41, pp. 1171-1181 (2006).

51. ANSYS FLUENT 12.1 User's Guide, ANSYS Inc., Canonsburg, PA (2009).

52. Versteeg, H.K. and Malalasekera, W. An Introduction to Computational Fluid Dynamics: The Finite Volume Method, Addison-Wesley, Boston, MA (1996).

53. Davidson, L. and Fontaine, J.R. "Calculation of the flow in a ventilated room using different finite difference schemes and different treatments of the walls", CLIMA 2000, Yugoslavia, Sarajevo (1989).

54. Sajadi, B., Saidi, M.H., Ahmadi, G., Kenney, S.M., and Taylor, J. "On the induced airflow and particle resuspension due to a falling disk", Particulate Science and Technology, 31, pp. 190-198 (2013).

55. Tian, Z.F., Tu, J.Y., Yeoh, G.H, and Yuen, R.K.K. "Numerical studies of indoor airflow and particle dispersion by large eddy simulation", Building and Environment, 42, pp. 3483-3492 (2007).

56. Posner, J.D., Buchanan, C.R., and Dunn-Rankin, D. "Measurement and prediction of indoor air flow in a model room", Energy and Buildings, 35, pp. 515-526 (2003).

57. Sajjadi, H., Salmanzadeh, M., Ahmadi, G., and Jafari, S. "Simulations of indoor airflow and particle dispersion and deposition by the lattice Boltzmann method using LES and RANS approaches", Building and Environment, 102, pp. 1-12 (2016).

58. Luscuere, P.G., Lemaire, T.D., and Ham, P.J. "Improvement capabilities of operating theatres with the help of computer flow modeling", Proceedings of Indoor Air, Helsinki, Finland (1993).

59. Tinker, J.A. and Roberts, D. "Indoor air quality and infection problems in operating theatres", Proceedings of the 2nd European Conference on Energy Performance and Indoor Climate in Buildings (EPIC), Lyon, France (1998).

\section{Biographies}

Behrang Sajadi is an Assistant Professor in the School of Mechanical Engineering at University of Tehran, Iran. His current research interests include aerosol mechanics, indoor air quality, energy modelling, heat transfer enhancement in refrigeration systems, and novel HVAC and refrigeration systems.

Mohammad Hassan Saidi is a Professor in the School of Mechanical Engineering at Sharif University of Technology, Iran. His current research interests include MEMS, heat transfer enhancement in boiling and condensation, modeling of pulse tube refrigeration, vortex tube refrigerators, indoor air quality and clean room technology, energy efficiency in home appliances, and desiccant cooling systems.

Goodarz Ahmadi is a Professor of Mechanical and Aeronautical Engineering at Clarkson University, NY. He has been awarded the title of "Clarkson Distinguished Professor." Some of his research interests include multiphase and granular flows, three-phase slurry flows, aerosols, micro-contamination control, turbulence modeling, stability of fluid motions, continuum mechanics, nonlinear random vibrations, and earthquake engineering. 